Marquette University

e-Publications@Marquette

College of Education Faculty Research and

Publications

Education, College of

$1-1-2011$

Selecting ELL Textbooks: A Content Analysis of Language-Teaching Models

Jeffrey LaBelle

Marquette University

Published version. Bilingual Research Journal, Vol. 34, No. 1 (2011): 94-110. DOI. (C) 2011 National Association for Bilingual Education (NABE). Used with permission. 


\title{
Selecting ELL Textbooks: A Content Analysis of Language-Teaching Models
}

\author{
Jeffrey T. LaBelle \\ Marquette University
}

\begin{abstract}
Many middle school teachers lack adequate criteria to critically select materials that represent a variety of L2 teaching models. This study analyzes the illustrated and written content of 33 ELL textbooks to determine the range of L2 teaching models represented. The researchers asked to what extent do middle school ELL texts depict frequency and variation of language-teaching models in illustrations and written texts. Using content analysis, they measured the range of depiction of the 4 language-teaching models and concluded that 4 of the 33 textbooks had considerable to extensive frequency and variation of L2 teaching models.
\end{abstract}

\section{INTRODUCTION}

Middle school teachers in Milwaukee, much like cities across the United States, struggle to identify effective and contextually appropriate textbooks for teaching English to students who are immigrants or children of immigrants (Case, Ndura, \& Righettini, 2005). Indeed, the urgency of addressing these concerns is brought home by predictions that "by 2030 nearly 40 percent of the school age population will speak a language other than English at home" (Freeman \& Freeman, 2007 , p. 5). Often counting on a limited number of textbooks available for middle school ELLs, many of these instructors have little or no information about the type of language-teaching models represented in these textbooks. An analysis of the content of these textbooks would provide one source of data to help teachers choose textbooks for middle school ELL students that would be suitable for their culturally and linguistically diverse students. García (2000) observes that ELLs, whether they are immigrants or born of immigrant parents, are less likely than their peers to have received the types of early childhood prereading scaffolding that many instructors expect. With this tendency in mind, a more critical analysis of the language-teaching models employed in ELL textbooks would assist instructors in selecting more effective and appropriate methods to scaffold ELLs even from their earliest years in the classroom.

Jeffrey T. LaBelle is Assistant Professor in Marquette University's College of Education. He earned his doctorate in international and multicultural education from the University of San Francisco in 2005, where he subsequently taught for 2 years. His teaching and research interests focus on sociolinguistics, multicultural education, and immigrant English language learning.

Address correspondence to Jeffrey T. LaBelle, Marquette University, College of Education, P.O. Box 1881, Milwaukee, WI 53201. E-mail: jeffrey.labelle@ marquette.edu 
Certainly one must recognize that second-language teaching is a complex process that seems to defy strict categorization (Adamson, 2005). However, some dominant models can be used to classify pedagogical approaches, techniques, and methods employed in a particular textbook (Brown, 2004). Different theorists have categorized ELL approaches in a wide range of frameworks (Adamson, 2005; Brown, 2004; Celce-Murcia, 2001). For clarity and simplicity, I have divided these approaches into the following four overarching models, within which variations of each can be situated. During the 20th century, linguists developed various theories of second-language acquisition (Chomsky, 1965; Krashen, 1985; Long, 1985; McLaughlin, 1987; Skinner, 1957). Each of these theories has furthered linguistic understanding of the factors involved in the acquisition of English by nonnative speakers. The various theories of Second Language Acquisition (SLA) can be divided into the following four general models:

1. Behaviorist: A language-teaching approach that emphasizes drills and repetition, audiolingual techniques, and/or eliciting responses stimulated by some external motivators as developed by such theorists as Lado (1957), Asher (1977), Lozanov (1978), and others.

2. Innatist: A language-teaching approach that focuses upon innate or natural abilities that help the student acquire the second language, e.g., the acquisition-learning, monitor, natural order, input, and affective filter hypotheses of Krashen (1985).

3. Cognitive/Attention-Processing: A language-teaching approach that centers upon how information is processed, e.g., whether it is controlled or automatic; focal or peripheral as developed by McLaughlin (1987), as well as whether it is implicit or explicit linguistic knowledge (Bialystok, 1990; Ellis, 1997; Ellis et al., 2009).

4. Social Constructivist/Interactionist: A language-teaching approach that pays attention to the dynamic interaction between learners and teachers (Gebhard, 2006), modified interaction, comprehensible input, and the zone of proximal development (Vygotsky, 1978) as applied by Long (1985).

From a theoretical perspective, this study established a protocol for the ongoing examination of ELL textbooks currently in use in middle schools. Many classroom instructors rely on their own personal judgment or intuition to select texts for their students or simply depend upon the textbooks approved by their district, school board, or nonprofit corporation. Some may lack the knowledge or even awareness of the extent to which their textbooks represent a variety of L2 teaching models. I contend that a more critical analysis of textbooks would lend a broader and more detailed description of the teaching models depicted, as well as raise the consciousness of educators in this regard. Because textbooks play a big part in how teachers conduct the curriculum in the classroom with ELLs, such a critical analysis is essential to assist them in the improvement of teaching and learning. Hence, the results of this study are intended to help instructors to make more fully informed judgments in their intentional choices of ELL textbooks. Furthermore, the coding instrumentation used to analyze the content of the particular textbooks chosen for this study serves as a tool for any classroom teacher to analyze and replicate this analysis on his or her own textbooks. It is my hope that the technique and protocol of this study can be generalized to assist any middle school teacher in the critical selection of contextually appropriate ELL textbooks. 


\section{THEORETICAL FRAMEWORK}

This study is grounded in the conceptual framework of four overarching trends or approaches to L2 teaching that I have operationally defined previously as language-teaching models. I have used the term model as synonymous with approach to distinguish these from classroom methods and techniques (Celce-Murcia, 2001). Each of these models is unique in its presuppositions as well as in the variety of methodologies and techniques that are represented within its theoretical approach. For example, the behaviorist model provides the theoretical basis for such teaching methodologies or techniques as Audio-Lingual Pedagogy (Lado, 1957), Total Physical Response (TPR) (Asher, 1977), and Suggestopedia (Lozanov, 1978). As stated previously, textbooks impact the ways in which instructors plan their ELL curriculum. In fact, these various teaching models are commonly embedded in those textbooks in both illustrated and written representation. Let us briefly examine these four general models in L2 teaching to review their methods, values, and applications.

The Behaviorist approach to L2 teaching is unique because it relies mostly on behavioral responses to stimuli. The historical audio-lingual approach, developed originally for military purposes, is one example of this type of L2 teaching model. One noteworthy value of this approach is the immediacy of the results in stimulating the production of sounds and meaningful utterances in the second language. Typical techniques in these methods are repetition, drills, and memorization.

The Behaviorist model of language acquisition supports the notion that humans acquire language through the senses as a response to a stimulus in the environment much as animals learn behaviors through training. Skinner (1957), one of the chief proponents of this approach, developed the notion of operant conditioning. By this term, he referred to the way in which a human being emits a response without necessarily observing stimuli. Building upon Skinner's concept of operant conditioning, behaviorist theorists proposed that, in order to maintain newly acquired language, one must receive ongoing reinforcement (Asher, 1969; Lozanov, 1978; Schuster, Benítez-Borton, \& Gritton, 1976).

This particular approach to language acquisition fostered the idea that language could be learned through repetition and constant stimuli, such as listening to audiotapes of the target language. In the historical context of post-World War II redevelopment and Cold War politics, Audio-Lingual Pedagogy (Lado, 1957) flourished as a medium of instruction for military personnel who were employed for purposes of national defense, foreign espionage, or infiltration of antidemocratic movements within the United States and around the globe. This same effort served as a testing ground for high school foreign language curricula that abounded in the decades immediately following World War II. By rigorous, disciplined training of aural comprehension and oral sound production, these behaviorist techniques yielded some positive results in speaking and listening skills in a foreign language.

The Innatist or Natural approach built upon the groundbreaking work of Noam Chomsky (1975). It is unique in the way in which it taps into the natural language ability or Universal Grammar (UG) of the student. It values the inborn or natural inclinations of the language students present in their developing first-language ability that can then be transferred, adapted, or applied to L2 learning (Krashen, 1985). Most frequently this model employs techniques such as role-playing, conversations, contextualized reading, and thematic writing, with special care 
to progress at a natural pace, which guides the student through stages of the learning process appropriate for the level of the L2 learner.

The Innatist second-language acquisition theory underscores the evidence of an innate ability in infants and children to decipher and decode language. Chomsky (1965) supported the notion of a Language Acquisition Device (LAD), an inborn element of each human being that aids in the formulation of patterns of words and concepts. McNeill (1970) indicated that LAD consists of four innate linguistics properties: (a) the ability to distinguish speech sounds from others in the environment, (b) the ability to organize linguistic data into various classes that can later be refined, (c) the knowledge that only a certain kind of linguistic system is possible and that other kinds are not, and (d) the ability to engage in constant evaluation of the developing linguistic system so as to construct the simplest possible system of the available linguistic input.

As an innatist, Krashen (1985) developed a model later called the input hypothesis, which is really five interrelated hypotheses. These are (a) acquisition-learning, (b) monitor, (c) natural order, (d) input, and (e) affective filter. Krashen claims that adults have two distinct means of internalizing a language, an intuitive or subconscious means called acquisition and a conscious process called learning. The monitor referred to above is a device used only for correcting errors in learning as Krashen defines it. The natural order refers to the hypothesis that people acquire language rules in a predictable natural order. Then there is the hypothesis of the input an acquirer can handle defined as $i+1$, that is, one new input at a time. Finally, the affective filter must be low so as to allow acquisition to occur in a less impeded fashion, i.e., reduced anxiety, etc.

The Cognitive or Attention-Processing approach is predominantly a psycholinguistic one and relies heavily on drawing upon the levels of consciousness or awareness of the student. This L2 teaching model values the individual L2 learner's personal reasoning abilities to recognize and process information. Its techniques or applications underscore a learner-centered approach to L2 acquisition. Some have critiqued this theoretical approach because it focuses too much "on psycholinguistic processes in the abstract and does not consider the social context of L2 learning" (Tarone, 2000, p. 182).

As a cognitive linguist, McLaughlin (1987) presented the Attention-Processing model. This model of second-language acquisition distinguished between focal and peripheral attention to formal properties of language by the adult. McLaughlin saw a continuum of attention in which less or more attention is paid to the task at hand, that is, either focusing centrally or on the periphery. Rather than define attention in terms such as conscious and subconscious, McLaughlin emphasized the processing of information and the level of attention given to it as either more focal or more peripheral. This reflects more accurately the human experience described by modern developmental psychology (Fodor, 1983; Piaget, 1973; Vygotsky, 1978) and allows for the variations that occur in human learning processes.

By further subdividing attention processing into controlled and automatic categories, McLaughlin set up four quadrants that plot quite accurately the range of learners as they progress through the continuum of SLA. Each of these four quadrants examines the performance of the language learners in a particular setting. For example, if learners are in a test situation, they pay more focal attention in processing the information and do so in a more automatic way. In contrast, when one assesses the performance of language learners in a communication or dialogue setting, the attention is more peripheral than the exam situation, but still a rather automatic processing mechanism is employed. 
Finally, the Social Constructivist or Interactionist approach comes at L2 acquisition from a sociolinguistic perspective, that is, viewing language as learned in relationship with other human beings. It values the social dimensions, the environmental factors, and the interpersonal effects of L2 learning in a social context. This approach underscores the need for conversation, contextualization, and real thematic content in L2 learning. Many theorists see this approach as a response to concerns among linguists that the "obsession with the decontextualized, autonomous learner has prevented us from conceptualizing SLA as a situated, integrated, sociocognitive process. .. . just as surely as language is social, so is its acquisition" (Atkinson, 2002, pp. 526527). Atkinson also emphasizes that input and interaction are essential parts of a "sociocognitive whole" including both nonlinguistic (e.g., gestures, facial expressions, etc.) and linguistic dimensions. Recognizing that these nonlinguistic elements vary with different language communities (Saville-Troike, 1976), this approach takes into account the social context in which the language is constructed.

Social constructivists consider language acquisition a result of several factors that are ultimately dependent upon socialization and usage to balance the interplay between acquired and innate learning. Researchers began to recognize that language was one manifestation of the cognitive and affective ability to deal with the world, with others, and with the self (McLaughlin, 1987; Vygotsky, 1978). In addition, this model strives to get at the functional levels of meaning constructed through social interaction. Long (1985) promoted his Interaction Hypothesis that built upon Krashen's (1985) Input Hypothesis. In this theory, Long contended that interaction, as well as input, is a major factor in the process of SLA. Drawing heavily from Vygotsky's (1978) concept of zones of proximal development, social constructivists theorize that learners actually construct their new language as mediated by social interaction. Furthermore, Fillmore (1993) pointed out the important roles that teachers, parents, and the entire community play in helping children develop their second language in a multicultural environment. In short, social constructivists consider not only the individual language learner in the process of SLA, but also the social context in which the learner interacts.

Several other approaches to L2 teaching could have been cited here that go beyond the scope of each of these four categories or are a recombination of elements of two or more of these approaches. For example, some have espoused critical or sociocultural approaches to language acquisition and language learning (Canale \& Swain, 1980; Celce-Murcia, 2007; McKay \& Hornberger, 1996). However, I have chosen to limit the range of categories to these four to provide a conceptual framework and content analysis that are more accessible and more readily applicable to ELL middle school classrooms. In addition, this conceptual framework enables the coders to organize the data collection in a way that allows for more direct and succinct analysis.

\section{RESEARCH QUESTION}

In my analysis of the ELL textbooks, I sought to determine the extent to which the selected corpus exhibited illustrated and written content that included a diverse range of L2 teaching models. The results of this content analysis provide a resource to ELL instructors in selecting textbooks that appeal to the variety of L2 teaching models often needed in ELL classrooms. This need is due in part to the variation in learning strategies that middle school children possess. On their part, ELL teachers frequently employ a broad range of teaching methodologies because 
of the challenges such a variation in learning strategies presents. In keeping with this prevalent pedagogical practice of varied and multiple methodologies, ELL textbooks that exhibit a broader range of L2 teaching models would provide instructors an increased likelihood of accessing and scaffolding the diverse learning strategies exhibited in the multicultural ELL classroom contexts (LaBelle, 2010; White, 2008). To that end, this research study sought to answer the following question: To what extent do middle school ELL texts depict frequency and variation of languageteaching models in illustrations and written texts?

\section{METHOD}

The researchers chose content analysis as the research method for this study because it could most effectively review the frequency and variation of types of L2 teaching models. Weber (1990) indicates that "Content analysis is a research method that uses a set of procedures to make valid inferences from text" (p. 9). As simple as that may sound, it must be noted that content analysis enjoys a wide range of techniques and applications in the social sciences. Some researchers contend that content analysis is a more quantitative approach, while others view it as necessarily qualitative due to its tendency to use induction in drawing conclusions and recommendations for further research. However, George (2009) insists:

Researchers have long debated the respective merits of "quantitative" and "qualitative" approaches to content analysis. ... Most writers on content analysis have made quantification a component of their definition of content analysis. In effect, therefore, they exclude the qualitative approach as being something other than content analysis. (p. 144)

In spite of these divergent and contrastive views, the foremost proponents of this type of method (Krippendorff, 2004; Neuendorf, 2002; Weber, 1990) build their definitions upon Berelson's (1952) definition of content analysis as “... . a research technique for the objective, systematic, and quantitative description of the manifest content of communication" (p. 18). Weber (1990) adds that this method ". . . uses a set of procedures to make valid inferences from text" (p. 9). Clearly, his definition underscores the inductive aspects of this method. Neuendorf (2002) posits that this is a "scientific method ... and is not limited as to the types of variables that may be measured or the context in which the messages are created or presented" (p. 10). In essence, Krippendorff (2004) concurs with Neuendorf (2002), at the same time emphasizing the importance of ". . . making replicable and valid inferences from texts (or other meaningful matter) to the contexts of their use" (p.18). This distinction points quite nicely to the value of analyzing the content of textbooks actually in use in the Milwaukee middle school context. Finally, it should be noted that crucial to conducting such analysis is the coding that must be done with great care and exactness. To that end, Liamputtong and Ezzy (2005) stress that this type of analysis refers ". . . to data analysis that involves the identification of categories prior to coding" (pp. 260-261).

Then just what is the primary purpose of content analysis? George (2009) answers this query quite succinctly:

Quantitative content analysis is, in the first instance, a statistical technique for obtaining descriptive data on content variables. Its value in this respect is that it offers the possibility of obtaining more precise, objective, and reliable observations about the frequency with which given content characteristics 
occur either singly or in conjunction with one another. In other words, the quantitative approach substitutes controlled observation and systematic counting for impressionistic ways of observing frequency of occurrence. (p. 144)

This purpose fits the present study's goal of coding precisely the frequency of L2 teaching models in the content of a series of ELL textbooks. Such "controlled observation and systematic counting" help quantify the frequency and variation with which these models occur rather than presenting anecdotal analysis that is extremely subject to the impressions of the researchers.

In order to carry out the content analysis and gather data regarding L2 teaching models, the researchers conducted a pilot study to solicit feedback for validity. The panel for this pilot study consisted of three graduate students and three faculty members, which included both researchers in the study. This panel of field practitioners and academicians was asked to review the initial coding instruments to determine if the instruments validly measured the content of a sample text for the indicated theme. Feedback from the members of the validity panel was then incorporated into the final coding instruments (Appendix B), which were later used to conduct the actual content analysis reported here. The researchers strove to make these coding instruments as clear and thorough as possible. "The goal in creating codebooks and coding forms is to make the set so complete and unambiguous as to almost eliminate the individual differences among coders" (Neuendorf, 2002, p. 132).

Because coding is done individually, it is imperative that sufficient training take place. However, "Final coding is to be done by each coder individually; at this stage, it is not a consensus-building process. Consensus is useful only during training, pilot, and revision stages" (Neuendorf, 2002, p. 133). Ultimately, some variation and divergence of judgment will result in spite of the great care taken to achieve consensus during the first phases of the pilot project.

To that end, the validity panel expressed several concerns and recommendations to the researchers in order to improve the validity of the instrumentation for language-teaching models. The panel recommended that care should be taken when drawing conclusions or inferences from these categories. Another member of the panel asked for clarification as to whether the coder should mark one occurrence for each person depicted or consider the photo as whole. "The validity of the coding process is the degree to which the theoretically relevant features of the answers are represented in the codes" (Hak \& Bernts, 2009, p. 221). The panel's recommendations were incorporated into the techniques employed by the coders in analyzing the content of the corpus. The researchers then conducted a pilot reliability assessment "on a randomly selected subsample of the total sample message pool before the study [began] in earnest" (Neuendorf, 2002, p. 146).

Finally, the researchers met in May 2008 to participate in a 2-hr training session in which they practiced coding a sample corpus taken from a segment of the Access English text other than the third chapter or unit. The researchers' coding consisted of placing a mark in ink by hand for each occurrence of the L2 teaching models indicated in the coding instruments when analyzing either illustrations or text for that particular category. They discovered and made clarifications regarding the definitions of the various language-teaching models developed in the coding instrumentation. The researchers met weekly over the course of 2 months to discuss any further concerns in the interpretation of the coding instruments and to clarify any differences to ensure intercoder reliability, that is ". . . the amount of agreement or correspondence among two or more coders" (Neuendorf, 2002, p. 141). In essence, intercoder reliability is much more readily determined than validity because it is based upon ". . . whether a coding of an answer is identical to another 
coding of the same answer, whether done at another time by the same coder or at the same time by another coder. . . Reliability is a matter of computation" (Hak \& Bernts, 2009, p. 221).

For this reason, special care was taken in the training of coders as well as the communication between the coders to ensure accurate computation of frequency and variation of languageteaching models exhibited in both illustrations and written texts. In addition, the coders were meticulous in applying the instructions as set forth in the coding instruments reviewed by the validity panel. These measures were taken to enhance and improve the reliability of the coders as indicated by Hak and Bernts (2009), who recommend "reliability can be improved by . . . coding in pairs of coders, developing more detailed instructions, selecting professional coders (e.g., the researcher's colleagues or graduate students) and, last but not least, coder training" (p. 222).

To select the sample corpus for content analysis, the researchers first collected copies of all the 64 ELL texts used in eight middle school classrooms. They identified these eight middle schools, four public and four Catholic, after consulting principals, teachers, and directors of curriculum for recommended sites. All eight schools were located in neighborhoods with high immigrant populations of predominantly Latino, Southeast Asian, and Somali families. From these texts, they selected only those that were actual student textbooks, excluding teacher manuals, teacher editions, student workbooks, and trade books. From the 64 representative books, 33 (slightly more than half) were chosen as appropriate for the study based upon their scope, i.e., actual student texts in contrast to student workbooks or teacher editions. Although these texts represent a variety of ELL texts from academic content areas, a vast majority (27 out of 33) of the textbooks analyzed primarily represents content in language arts and literature. Only two textbooks represent each of the other content areas: mathematics (Access Math and Facts \& Figures), science (Access Science and Cause \& Effect), and social studies (Access American History and America's Story). Of particular note was the Access series that all eight middle schools utilized, in the case of the four public schools based upon district approval. (A complete listing of these 33 textbooks analyzed can be found in Appendix A).

The results of this sorting process were 33 textbooks from which the corpus under study was derived. Depending on how each textbook was organized (by chapters or units), the content analysis was conducted on the third chapter or unit of each of the 33 representative textbooks as a systematic, convenience sample. Taken together, these chapters or units formed the corpus of the study. The researchers gathered the data regarding language-teaching models by means of a self-designed coding instrument consisting of four categories, one for each type of language teaching models (Appendix B). The coding was conducted in two parts: first, language-teaching models as exhibited in illustrations; second, language-teaching models as exhibited in written text. Coding was based upon each researcher's judgment of his or her observations and interpretations of the photos, drawings, illustrations, or actual narrative texts within the corpus chosen for consideration.

The two researchers each coded either 16 or 17 of the textbooks (for a total of 33) that formed the corpus by using the original copies of the textbooks, printed instrumentation sheets, and marked the occurrences of types of L2 teaching models depicted in chapter or unit 3 of that particular textbook. Samples of this coding (conducted in the pilot study of chapter one of Access English) are included in Appendix B. Once the coder finished an individual third chapter or unit of a textbook, he or she moved on to the next textbook. This coding was conducted over a period of 2 months, in June and July of 2008. 
What makes the use of content analysis so appropriate to this particular study is its contextual applicability. Krippendorff (2004) maintains that "Content analysis is a research technique for making replicable and valid inferences from texts (or other meaningful matter) to the contexts of their use" (p. 18). That is why the purpose of this analysis of ELL middle school textbooks was not merely to determine the frequency and variation of L2 teaching models exhibited in the books, but also to provide ELL teachers with information that will help them to select textbooks they deem appropriate for their students.

After completing the coding of all 33 textbooks, I then tallied the total number of occurrences of each type of L2 teaching models and organized the data reports to display raw totals for the textbooks across the four models. Tables 1 and 2 group the textbooks in ranked order as extensive,

TABLE 1

Language-Teaching Models as Depicted in Illustrations by Textbook

\begin{tabular}{|c|c|c|c|c|c|}
\hline Title & Behaviorist & Innatist & Cognitive & Interactionist & Totals \\
\hline Access American History & 23 & 30 & 22 & 14 & 89 \\
\hline Access Math & 7 & 15 & 22 & 5 & 49 \\
\hline Turning Points 4 & 37 & 15 & 30 & 4 & 86 \\
\hline Voices in Literature, Gold & 14 & 10 & 21 & 7 & 52 \\
\hline ESL 4 & 5 & 13 & 17 & 4 & 39 \\
\hline High Point & & 1 & 31 & 22 & 54 \\
\hline Access English & 2 & 11 & 6 & 1 & 20 \\
\hline Access Science & 1 & 3 & 4 & 3 & 11 \\
\hline Cause \& Effect & & 22 & 2 & & 24 \\
\hline ESL 5 & 1 & 4 & 8 & 1 & 14 \\
\hline Voices in Literature, Bronze & 1 & 2 & 8 & 7 & 18 \\
\hline Voices in Literature, Silver & & 2 & 3 & 6 & 11 \\
\hline 20th Century American Short Stories & & 1 & 1 & & 2 \\
\hline America's Story & & 1 & 3 & 1 & 5 \\
\hline Content Connection & & 2 & 1 & 3 & 6 \\
\hline English, Yes! Beginning & & 5 & 2 & 2 & 9 \\
\hline English, Yes! Transitional & 1 & & 1 & & 2 \\
\hline Fact \& Figures & & 1 & & 2 & 3 \\
\hline Living, Learning, Literature & 3 & 2 & 3 & & 8 \\
\hline Look, I Can Talk More! & 1 & 1 & 1 & 1 & 4 \\
\hline Look, I Can Talk & 3 & & 3 & & 6 \\
\hline Sam and Pat 1 & 4 & & & & 4 \\
\hline Turning Points 3 & & 3 & 7 & 1 & 11 \\
\hline \multicolumn{6}{|l|}{ A World of Fiction } \\
\hline \multicolumn{6}{|l|}{ Adventures of Tom Sawyer } \\
\hline \multicolumn{6}{|l|}{ English, Yes! Intermediate } \\
\hline \multicolumn{6}{|l|}{ English, Yes! Introductory } \\
\hline \multicolumn{6}{|l|}{ In Good Company, \#3 } \\
\hline \multicolumn{6}{|l|}{ Pizza Tastes Great! } \\
\hline \multicolumn{6}{|l|}{ Readings in Cultural Literacy } \\
\hline \multicolumn{6}{|l|}{ Sam and Pat 2} \\
\hline \multicolumn{6}{|l|}{ Teen Scene } \\
\hline Teen Stories & & & & & \\
\hline
\end{tabular}


TABLE 2

Language-Teaching Models as Depicted in Written Text by Textbook

\begin{tabular}{|c|c|c|c|c|c|}
\hline Title & Behaviorist & Innatist & Cognitive & Interactionist & Totals \\
\hline Access American History & 21 & 6 & 25 & 18 & 70 \\
\hline Access Math & 51 & 25 & 94 & 29 & 199 \\
\hline English, Yes! Beginning & 49 & & 44 & 8 & 101 \\
\hline High Point & 79 & 2 & 45 & 14 & 140 \\
\hline Voices in Literature, Bronze & 37 & 1 & 11 & 13 & 62 \\
\hline Voices in Literature, Gold & 42 & 5 & 33 & 34 & 114 \\
\hline Access English & 9 & 6 & 12 & 8 & 35 \\
\hline Cause \& Effect & 29 & & 1 & 2 & 32 \\
\hline English, Yes! Introductory & 9 & 4 & 8 & 10 & 31 \\
\hline ESL 5 & 10 & 4 & 8 & 4 & 26 \\
\hline Look, I Can Talk & 20 & 10 & 8 & 3 & 41 \\
\hline Turning Points 4 & 15 & 3 & 23 & 7 & 48 \\
\hline Voices in Literature, Silver & 9 & 6 & 3 & 13 & 31 \\
\hline A World of Fiction & 4 & 5 & 8 & 3 & 20 \\
\hline Access Science & 6 & 5 & 4 & 6 & 21 \\
\hline America's Story & 7 & 1 & 3 & & 11 \\
\hline Content Connection & & 11 & 18 & & 29 \\
\hline English, Yes! Intermediate & 6 & 9 & 7 & 3 & 25 \\
\hline English, Yes! Transitional & 6 & & 6 & 1 & 13 \\
\hline ESL 4 & 5 & 1 & 6 & 7 & 19 \\
\hline Fact \& Figures & 12 & 3 & 4 & 4 & 23 \\
\hline Look, I Can Talk More! & 3 & 2 & 7 & 1 & 13 \\
\hline Pizza Tastes Great! & 4 & 6 & 6 & 5 & 21 \\
\hline Readings in Cultural Literacy & 7 & 2 & 7 & 3 & 19 \\
\hline Teen Scene & 5 & 2 & 4 & 1 & 12 \\
\hline Teen Stories & 10 & 3 & 4 & 3 & 20 \\
\hline Turning Points 3 & 6 & 2 & 1 & 4 & 13 \\
\hline 20th Century American Short Stories & 1 & 1 & 5 & 3 & 10 \\
\hline Adventures of Tom Sawyer & & & 1 & & 1 \\
\hline In Good Company, \#3 & & & 7 & 1 & 8 \\
\hline Living, Learning, Literature & 5 & & & & 5 \\
\hline Sam and Pat 1 & 5 & & 3 & & 8 \\
\hline Sam and Pat 2 & 7 & 2 & & & 9 \\
\hline
\end{tabular}

considerable, some, little, and none based upon the following rubric that measured frequency and variation of depiction of L2 teaching models:

1. Extensive: $>50$ frequencies $+>4$ models represented

2. Considerable: $26-50$ frequencies +3 models represented

3. Some: $11-25$ frequencies +2 models represented

4. Little: 1-10 frequencies and/or 1 model represented

5. None: 0 frequency; 0 model represented

For example, in Table 1 the first four textbooks listed (Access American History through Voices in Literature, Gold) are extensive in their depiction of L2 teaching models. The next two textbooks (ESL 4 and High Point) are ranked as having considerable depiction of L2 teaching models since 
they meet the criteria of 26-50 frequencies and at least three models represented. In short, the textbooks are listed from most extensive depiction to none in ranked order from top to bottom in both Table 1 and Table 2

\section{RESULTS}

Of the 33 textbooks analyzed for breadth of teaching models, only four met the criteria to be ranked as extensive in the frequency and number of models represented in illustrations and only six in written text. Furthermore, of these two sets of textbooks judged as extensive in their depiction, three textbooks stand out as extensive in both illustrations and written text: Access English; Access Math; and Voices in Literature, Gold. These particular ELL textbooks are exemplary in their wide range and frequency of the ELL teaching models they employ. I should also note that another textbook, High Point, exhibited considerable breadth in its representation of languageteaching models in both illustrated and written forms. No such content analysis of L2 teaching models has been found in previous literature on this topic.

In analyzing the data for L2 teaching models depicted in illustrations, the researchers discovered that the vast majority of the textbooks, 27 in total, fell below the extensive or considerable categories. It would appear that this is due at least in part to the challenge of depicting L2 teaching models in illustrated form. Nevertheless, the results suggest that more effort is needed in this area to develop textbooks that illustrate the models of the L2 teaching methodologies as well as to represent them in the written text itself.

Turning my attention to the results in Table 2, I discovered that 13 of the 33 textbooks analyzed had considerable or extensive representation of L2 teaching models. In addition, I observed that the majority of the textbooks exhibited fewer depictions of Innatist teaching models than the other three categories. Behaviorist and Interactionist models predominate in general, with some notable exceptions: Access Math, Turning Points 4, and Content Connections. Those three textbooks have more frequency of Cognitive models represented in written text than in the other three models. These results suggest an imbalance in some textbooks that were not among the 13 rated as considerable or extensive in their depiction of L2 teaching models.

\section{CONCLUSIONS}

From the analysis of the data collected, classroom teachers can readily observe which textbooks are most diverse in regard to their L2 teaching models. Furthermore, this information can help instructors make better-informed decisions when selecting instructional materials for ELL classes. By providing teachers this ranking of textbooks of most extensive to least extensive depiction of L2 teaching models, I hope that middle schools ELL instructors can more critically choose the best and most appropriate textbooks for their students. Furthermore, the coding instrument included in Appendix B can also serve them to analyze the content of additional textbooks of their choosing.

In contrast, those textbooks that provide little or no diversity of teaching models are called into question as to their appropriateness and effectiveness in responding to the wide variety 
of learning styles of the students. In particular, cultural and linguistic variations make the selection of textbooks more complex and tenuous. Since students in most ELL classrooms come from a variety of cultural and linguistic contexts, a one-size-fits-all approach (one which unfortunately dominates the field), is clearly misguided. One way in which the ELL instructor can improve or enhance L2 language learning is by critically selecting textbooks that employ the broadest range of L2 teaching models in illustrations and written text. In short, classroom teachers need to critically choose textbooks with more diverse teaching models that might scaffold a wider range of learning styles (Case, Ndura, \& Righettini, 2005). Otherwise, they will be faced with constantly searching for materials to supplement the variety of learning styles of the students. This would be a very time-consuming and costly venture indeed.

Finally, classroom instructors would do well to take a critical view in their analysis of textbooks used to improve L2 learning (Grady, 1997). It would be quite insufficient to rely solely on an analysis of the content of textbooks regarding L2 teaching models to determine if the themes depicted in textbooks match the lived reality of the ELLs (Gilmore, 2007). By utilizing ELL textbooks that reflect the widest range of L2 teaching models, educators can more effectively engage and motivate students to learn English as they embrace their emerging language identities (Dörnyei \& Ushioda, 2009).

\section{Limitations}

Since content analysis involves no human subjects, no specific population of participants was under investigation in this study. However, it must be noted that the corpus selected for this content analysis represents only a selection of 33 student textbooks in use at the time of the study in eight middle schools in Milwaukee, Wisconsin. Since the corpus did not include all middle school ELL texts currently available in publication and use in the United States, the results of this study cannot be generalized to all ELL textbooks. Rather, the transferability of this study is limited to the schools and textbooks under investigation. Nevertheless, the recommendations and conclusions indicated here may benefit schools and educators in other contexts in the United States who use the same or similar student textbooks. Furthermore, the protocol or coding instrumentation developed for this study can be replicated to conduct content analysis on other textbooks in other settings.

Still, ELL teachers should be cautious to jump to the conclusion that those particular textbooks are the best or most appropriate for their own classrooms. Other factors need to be taken into account. These include, but are not limited to, the ethnic composition of their particular classroom, the demographic context in which the students live, and the L2 learning strategies involved. In short, the representation of diverse L2 teaching methods in a given textbook does not necessarily mean that a particular textbook is the most appropriate one for a group of students.

Although sample figures, illustrations, or texts have not been displayed in this study for the benefit of the reader, it must be recognized that teaching models are often difficult to recognize. The coding of L2 teaching models in this study was based upon associations made by the coders. These associations are dependent upon the individual researcher's judgment and observation of the selected corpus. To that end, some errors may have occurred due to limitations in perception and judgment. 


\section{Recommendations}

Middle school teachers, principals, district or diocesan superintendents, or anyone who is responsible for ELL textbook adoption should consider the results of this study in making decisions for ELL textbook selection. My conclusions indicate only four textbooks with a considerable to extensive range of depiction of L2 teaching models in both illustrations and written texts. These textbook choices are most likely appropriate for any particular school context. Nevertheless, those who teach and administrate in specific contexts will be the most indicated judges of ELL textbook choice. Some may wish to choose other textbooks that were ranked considerable to extensive in the range of depiction in only written texts, concluding that illustrated depiction is of lesser importance.

ELL teachers and their administrators need to be more fully informed of the L2 teaching models exhibited in the textbooks they currently use, as well as those they might select for future use. Such information enables them to more effectively plan and conduct their curricula as well as to improve student language-learning outcomes. The results of this study provide one source of information to assist them in their decisions. Professional ELL educators would do well to make use of the coding instrument when reviewing other textbooks not included in this content analysis. In any case, ELL teachers need to review their textbooks with a more critical eye, not just a cursory or limited view, to ensure the selection of materials that more effectively enhance and scaffold the learning of the ELL students in a given context (Case et al., 2005).

\section{Suggestions for Further Research}

Further study is needed to determine what occurs when learners actually attempt to use these recommended textbooks. The scope of the present study was to set up a protocol for analyzing the textbooks themselves. The next stage of research would include observations in instructional settings to collect information about the effectiveness of these same textbooks in actual pedagogical practice. In addition, more research is needed to study how L2 teaching models are affected by a variety of factors, including ethnicity, situational context, and language-learning strategies. It would be beneficial not only to research these factors separately, but also to assess how they interact to enhance or detract from L2 learning. To that end, in separate studies, I have set about to analyze the content of these same 33 textbooks for these other three factors. It is my hope that the combined results of these studies will further the goal of providing middle school teachers with more criteria to assist them in the selection of ELL textbooks they deem appropriate for their particular classrooms.

Some questions remain unanswered at the conclusion of this study. For example, one might question the relative importance of depicting teaching models in illustrations. Perhaps this has little or no impact on student language learning. More study is needed to examine the relationship between L2 teaching models and L2 learning styles. Future research that combines these two approaches might surface a more holistic view of the ways in which learning strategies and teaching models interplay.

Finally, recognizing that the present study did not solicit reactions from the L2 learners themselves, it would be enlightening to investigate how students with different learning styles or preferences might respond to these textbooks. Such qualitative research might generate some 
unique insights for further study and theory. "As more immigrants arrive in the United States, the need for increased attention to issues of SLA becomes more urgent” (LaBelle, 2007, p. 3).

\section{REFERENCES}

Adamson, H. D. (2005). Language minority students in American schools. Mahwah, NJ: Larwrence Erlbaum Associates. Asher, J. (1969). The total physical response approach to second language learning. Modern Language Journal, 53(1), $3-17$.

Asher, J. (1977). Learning another language through actions: The complete teacher's guidebook. Los Gatos, CA: Sky Oak Productions.

Atkinson, D. (2002). Toward a sociocognitive approach to second language acquisition. The Modern Language Journal, $86,525-545$

Berelson, B. (1952). Content analysis in communication research. New York, NY: Hafner.

Bialystok, E. (1990). Communication strategies: A psychological analysis of second language use. Oxford, England: Blackwell.

Brown, H. D. (2004). Principles of language learning and teaching (4th ed.). White Plains, NY: Pearson.

Canale, M., \& Swain, M. (1980). Theoretical bases of communicative approaches to second language teaching and testing Applied Linguistics, (1)1, 1-47.

Case, R. E., Ndura, E., \& Righettini, M. (2005). Balancing linguistic and social needs: Evaluating texts using a critical language awareness approach. Journal of Adolescent \& Adult Literacy, (48)5, 374-391.

Celce-Murcia, M. (Ed.). (2001). Teaching English as a second or foreign language. Boston, MA: Heinle \& Heinle.

Celce-Murcia, M. (2007). Rethinking the role of communicative competence in language teaching. In E. A. Soler \& M. P. Safont Jordà (Eds.), Intercultural language use and language (pp. 41-57). New York, NY: Springer.

Chomsky, N. (1965). Aspects of the theory of syntax. Cambridge, MA: MIT Press.

Chomsky, N. (1975). Reflections on language. New York, NY: Pantheon Books.

Dörnyei, Z., \& Ushioda, E. (Eds.). (2009). Motivation, language identity and the L2 self. Buffalo, NY: Multilingual Matters.

Ellis, R. (1997). SLA research and language teaching. Oxford, England: Oxford University Press.

Ellis, R., Loewen, S., Elder, C., Erlam, R., Philp, J., \& Reinders, H. (Eds.) (2009). Implicit and explicit knowledge in second language learning, testing and teaching. Buffalo, NY: Multingual Matters.

Fillmore, L. W. (1993). Educating citizens for a multicultural 21st century. Multicultural Education, 1(1), 10-12.

Fodor, J. A. (1983). The modularity of the mind. Cambridge, MA: The MIT Press.

Freeman, D. E., \& Freeman, Y. S. (2007). English language learners: The essential guide. New York, NY: Scholastic.

García, G. (2000). Lessons from research: What is the length of time it takes limited English proficient students to acquire English and success in an all-English classroom? Washington, DC: National Clearinghouse for Bilingual Education.

Gebhard, J. G. (2006). Teaching English as a foreign or second language: A self-development and methodology guide. Ann Arbor, MI: University of Michigan Press.

George, A. (2009). Quantitative and qualitative approaches to content analysis. In K. Krippendorff \& M. A. Bock (Eds.), The content analysis reader (pp. 144-155). Thousand Oaks, CA: Sage Publications, Inc.

Gilmore, A. (2007). Authentic materials and authenticity in foreign language learning. Language Teaching, 40, 97-118.

Grady, K. (1997). Critically reading an ESL text. TESOL Journal, 6(4), 7-10.

Hak, T., \& Bernts, T. (2009). Coder training: Explicit instruction and implicit socialization. In K. Krippendorff \& M. A. Bock (Eds.), The content analysis reader (pp. 220-233). Thousand Oaks, CA: Sage Publications, Inc.

Krashen, S. (1985). The input hypothesis. London, England: Longman.

Krippendorf, K. (2004). Content analysis: An introduction to its methodology (2nd ed.). Thousand Oaks, CA: Sage Publications, Inc.

LaBelle, J. T. (2007). Vietnamese American experiences of English language learning: Ethnic acceptance and prejudice. Journal of Southeast Asian American Education and Advancement, 2. Retrieved from http://epublications.marquette.edu/cgi/viewcontent.cgi?article $=1063 \&$ context $=$ edu_fac

LaBelle, J. T. (2010). Selecting ELL textbooks: A content analysis of L2 learning strategies. Journal of Language Teaching and Research, 1(4). Retrieved from http://epublications.marquette.edu/cgi/viewcontent.cgi?article= $1115 \&$ context $=$ edu_fac 
Lado, R. (1957). Linguistics across cultures: Applied linguistics for language teachers. Ann Arbor, MI: University of Michigan Press.

Liamputtong, P., \& Ezzy, D. (2005). Qualitative research methods. New York, NY: Oxford University Press.

Long, M. H. (1985). Input and second language acquisition theory. In S. M. Gass \& C. Madden (Eds.), Input in second language acquisition (pp. 356-387). Rowley, MA: Newbury House.

Lozanov, G. (1978). Suggestology and outlines of suggestopedy. New York, NY: Gordon and Breach.

McKay, S. L., \& Hornberger, N. H. (Eds.). (1996). Sociolinguistics and language teaching. New York, NY: Cambridge University Press.

McLaughlin, B. (1987). Theories of second language learning. London, England: Edward Arnold.

McNeill, D. (1970). The acquisition of language: The study of developmental psycholinguistics. New York, NY: Harper \& Row.

Neuendorf, K. A. (2002). The content analysis guidebook. Thousand Oaks, CA: Sage Publications, Inc.

Piaget, J. (1973). The child and reality: Problems of genetic psychology. New York, NY: Grossman Publishers.

Saville-Troike, M. (1976). Foundations of teaching English as a second language: Theory and method for multicultural education. Englewood Cliffs, NJ: Prentice-Hall, Inc.

Schuster, D. H., Benítez-Borton, R., \& Gritton, C. A. (1976). Suggestive, accelerative learning and teaching: A manual of classroom procedures based on the Lozanov method. Des Moines, IA: Society for Suggestive-Accelerative Learning and Teaching.

Skinner, B. F. (1957). Verbal behavior. New York, NY: Appleton-Century-Crofts.

Tarone, E. (2000). Still wrestling with context. Annual Review of Applied Linguistics, 20,181-198.

Vygotsky, L. (1978). Mind in society: The development of higher psychological processes. Cambridge, MA: Harvard University Press.

Weber, R. P. (1990). Basic content analysis (2nd ed.). Newbury Park, CA: Sage Publications, Inc.

White, C. (2008). Language learning strategies in independent language learning: An overview. In S. Hurd \& T. Lewis (Eds.), Language learning strategies in independent settings (pp. 3-24). Buffalo, NY: Multilingual Matters.

\section{APPENDIX A: TEXTBOOKS ANALYZED}

Ackert, P., Giroux de Navarro, N., \& Bernard, J. (1999). Cause \& effect: Intermediate reading practice. Boston, MA: Heinle \& Heinle Publishers.

Ackert, P., Giroux de Navarro, N., \& Bernard, J. (1999). Facts \& figures: Beginning reading practice. Boston, MA: Heinle \& Heinle Publishers.

Bernstein, V. (Ed.). (2001). America's story book one to 1865. Austin, TX: Steck-Vaughn Company.

Chamot, A. U., Cummins, J., Kessler, C., O’Malley, J. M., \& Fillmore, L. W. (1997). ESL: Accelerating English language learning. Book 4. Glenview, IL: ScottForesman.

Chamot, A. U., Cummins, J., Kessler, C., O’Malley, J. M., \& Fillmore, L. W. (1997). ESL: Accelerating English language learning. Book 5. Glenview, IL: ScottForesman.

Chips, B., Manzano, B., \& Terrell, T. D. (Eds.). (1987). Content connection. Northvale, NJ: Santillana.

Drayton, A. M., \& Skidmore, C. (1985). In good company: A skill-building reader. Reading, MA: Addison-Wesley Publishing.

Goodman, B. (Ed.). (1996). English, yes! Learning English through literature. Beginning level 1. Lincolnwood, IL: Jamestown Publishers.

Goodman, B. (Ed.). (1996). English, yes! Learning English through literature. Intermediate level 1. Lincolnwood, IL: Jamestown Publishers.

Goodman, B. (Ed.). (1996). English, yes! Learning English through literature. Introductory level 1. Lincolnwood, IL: Jamestown Publishers. 
Goodman, B. (Ed.). (1996). English, yes! Learning English through literature. Transitional. Lincolnwood, IL: Jamestown Publishers.

Great Source Education Group. (2005). Access: Building literacy through learning. American History. Wilmington, MA: Houghton Mifflin.

Great Source Education Group. (2005). Access: Building literacy through learning. English. Wilmington, MA: Houghton Mifflin.

Great Source Education Group. (2005). Access: Building literacy through learning. Math. Wilmington, MA: Houghton Mifflin.

Great Source Education Group. (2005). Access: Building literacy through learning. Science. Wilmington, MA: Houghton Mifflin.

Hartel, J., Lowry, B., \& Hendon, W. (Eds.). (2006). Sam and Pat beginning reading and writing 1. Boston, MA: The Thomson Corporation.

Hartel, J., Lowry, B., \& Hendon, W. (Eds.). (2006). Sam and Pat beginning reading and writing 2. Boston, MA: The Thomson Corporation.

Iantorno, G., \& Papa, M. (1994). Turning points: Communicating in English level 3. Reading, MA: Addison-Wesley Publishing Company.

Iantorno, G., \& Papa, M. (1994). Turning points: Communicating in English level 4. Reading, MA: Addison-Wesley Publishing Company.

Kanasky, W. F., Howard, E., \& Graham, P. A. (Eds.). (1993). Living, learning \& literature: Classic and contemporary works. Compton, CA: Santillana.

Koch, K. D., Mrowicki, L., \& Ruttenberg, A. (Eds.). (1988). Teen scene: Personal stories for students who are beginning to read. Palatine, IL: Linmore Publishing, Inc.

Koch, K. D., Mrowicki, L., \& Ruttenberg, A. (Eds.). (1990). Teen stories: Personal stories for students who are beginning to read. Palatine, IL: Linmore Publishing, Inc.

Marcus, S. (Ed.). (2006). A world of fiction: Twenty timeless short stories. White Plains, NY: Pearson Education.

Margulies, S., \& Crowell, C. E. (Eds.). (1997). Readings in cultural literacy: Topics across the curriculum. New York, NY: Educational Design, Inc.

McCloskey, M. L., \& Stack, L. (Eds.). (1996). Voices in literature, bronze. Boston, MA: Heinle.

McCloskey, M. L., \& Stack, L. (Eds.). (1996). Voices in literature, silver. Boston, MA: Heinle.

McCloskey, M. L., \& Stack, L. (Eds.). (1996). Voices in literature, gold. Boston, MA: Heinle.

McConochie, J. A. (Ed.). (1975). 20th century American short stories. New York, NY: Collier MacMillian.

Pickett, W. P. (2002). The pizza tastes great: Dialogs and stories (2nd ed.). White Plains, NY: Pearson Education.

Ray, B. (2000). Look, I can talk! A step-by-step approach to communication through TPR stories. Los Gatos, CA: Sky Oaks Productions, Inc.

Ray, B., Neilson, J., Cline, D., \& Stevens, C. (1998). Look, I can talk more! Student notebook: A step-by-step approach to communication through TPR stories. Los Gatos, CA: Sky Oaks Productions, Inc.

Schifini, A., Short, D., \& Tinajero, J. V. (2000). High point: Success in language, literature, content. Carmel, CA: Hampton-Brown.

Twain, M. (1993). The adventures of Tom Sawyer. Essex, England: Longman Group UK Limited. 


\section{APPENDIX B: \\ SAMPLE CODING INSTRUMENTS}

CODER:

DATE

BOOK TITLE:

Part 1: Please place a tally mark (I) in the table below to indicate the language-teaching models appearing in illustrations in the excerpt.

Examples:

1. You see a diagram that illustrates the steps that the student needs to take to process the information in a lesson.

2. You see an illustration that depicts individuals interacting to clarify the meaning of a new vocabulary word.

3. You observe that in the development of the lesson a very natural order from everyday life is followed.

You would record your observations as indicated in the table below.

\begin{tabular}{ll}
\hline Language-Teaching Models & \multicolumn{1}{c}{ Your Observations } \\
\hline Behaviorist Approach & \\
Innatist Approach & I (natural order is followed) \\
Cognitive Approach & I (steps to process the information) \\
Interactionist Approach & I (individuals interacting in picture) \\
\hline
\end{tabular}

Part 2: Please place a tally mark (I) in the table below to indicate the language-teaching models in the text appearing in the excerpt (written data only).

Examples:

1. You read, "When you finish the lesson, raise your hand."

2. You read, "Practice the following dialogue with another member of your class."

3. You read, "Listen and repeat."

You would record your observations as indicated in the table below.

\begin{tabular}{lc}
\hline Language-Teaching Models & Your Observations \\
\hline Behaviorist Approach & I “When you finish the lesson, raise your hand." \\
& I "Listen and repeat." \\
Innatist Approach & \\
Cognitive Approach & I "Practice the following dialogue with another member of \\
Interactionist Approach & your class." \\
\hline
\end{tabular}

